\title{
PROPOSTA DE APLICAÇÃO DE UM PLANO DE NEGÓCIOS NO PROJETO DE CRIAÇÃO DE UM SISTEMA DE FRANQUIAS
}

\author{
Rodrigo Henrique Lima Lemos \\ Centro de Tecnologia da Indústria Química e Têxtil (SENAI CETIQT) \\ Rua Magalhães Castro, 174 - Riachuelo, Rio de Janeiro - RJ, 20961-020 \\ rodrigo_nf@globomail.com \\ Marcone Freitas dos Reis \\ Centro de Tecnologia da Indústria Química e Têxtil (SENAI CETIQT) \\ Rua Magalhães Castro, 174 - Riachuelo, Rio de Janeiro - RJ, 20961-020 \\ marconefreis11@gmail.com \\ Marcos dos Santos \\ Instituto Militar de Engenharia (IME) \\ Praça General Tibúrcio, 80 - Praia Vermelha - Urca, Rio de Janeiro - RJ, 22290-270 \\ marcosdossantos_doutorado_uff@yahoo.com.br \\ Valéria da Silva Brito \\ Universidade Federal Fluminense (UFF) \\ Av. Visconde do Rio Branco, s/n - Centro, Niterói - RJ, 24020-140 \\ valeriasbrito@hotmail.com \\ Angélica Rodrigues de Lima \\ Centro de Tecnologia da Indústria Química e Têxtil (SENAI CETIQT) \\ Rua Magalhães Castro, 174 - Riachuelo, Rio de Janeiro - RJ, 20961-020 \\ angelicadelima.engprod@gmail.com
}

\section{RESUMO}

Empreendedorismo é um conceito que vem sendo abordado nas discussões acadêmicas e nos estudos sobre administração, haja vista a necessidade de se explorarem áreas antes não procuradas. Tal faro vem sendo verificado paralelamente ao processo de privatização que surgiu também com a abertura do comércio interno para a concorrência externa, que trouxe maior competitividade aos mercados. Nesse contexto, destaca-se o empreendedorismo, definido como um conjunto de hábitos e características pessoais com base na captação de ideias e iniciativas, transformadas em oportunidades de negócios. Está associado ao empreendedorismo e aos conceitos de desenvolvimento econômico, o aproveitamento das oportunidades e inovação. O presente estudo tem como proposta desenvolver um Plano de Negócio com auxílio do software SEBRAE 3.0, para criação de um sistema de franquias de uma barbearia e bar temático, onde seja possível inovar o modelo de gestão atual, alavancar e promover o empreendimento no mercado estético.

Palavra-chave: Plano de Negócios; Ferramentas de Gestão; Franquias. 


\begin{abstract}
Entrepreneurship is a concept that has been addressed in academic discussions and management studies, given the need to explore areas not previously sought. This has been seen in parallel with the privatization process that also emerged with the opening of internal trade to external competition, which brought greater competitiveness to markets. In this context, entrepreneurship stands out, defined as a set of habits and personal characteristics based on the capture of ideas and initiatives, transformed into business opportunities. It is associated with entrepreneurship and the concepts of economic development, seizing opportunities and innovation. The present study aims to develop a Business Plan with the aid of SEBRAE 3.0 software, to create a barber shop and thematic franchise system, where it is possible to innovate the current management model, leverage and promote the venture in the aesthetic market.
\end{abstract}

Keywords: Business Plan; Management Tools; Franchises.

\title{
Como Citar:
}

LEMOS, Rodrigo Henrique Lima; REIS, Marcone Freitas dos; SANTOS, Marcos dos; BRITO, Valéria da Silva. LIMA, Angélica Rodrigues de. Título do Trabalho. In: SIMPÓSIO DE PESQUISA OPERACIONAL E LOGÍSTICA DA MARINHA, 19., 2019, Rio de Janeiro, RJ. Anais [...]. Rio de Janeiro: Centro de Análises de Sistemas Navais, 2019.

\section{INTRODUÇÃO}

Empreendedorismo é um conceito que vem sendo abordado nas discussões acadêmicas e nos estudos sobre administração, haja vista a necessidade de se explorarem áreas antes não procuradas. Tal faro vem sendo verificado paralelamente ao processo de privatização que surgiu também com a abertura do comércio interno para a concorrência externa, que trouxe maior competitividade aos mercados. Nesse contexto, destaca-se o empreendedorismo, definido como um conjunto de hábitos e características pessoais com base na captação de ideias e iniciativas, transformadas em oportunidades de negócios. (FILION, 1997)

Está associado ao empreendedorismo e aos conceitos de desenvolvimento econômico, o aproveitamento das oportunidades e inovação. Para esse autor, “o empreendedor é aquele que destrói a ordem econômica existente pela introdução de novos produtos e serviços, pelo desenvolvimento de novas formas de criação ou pela exploração de novos recursos e materiais”. (SCHUMPTER, 1978 apud DORNELAS, 2008, p.22)

Cossete (1990) apud Wildauer (2010) afirma que, para facilitar a descoberta de oportunidades de negócio, é também adequado cultivar o pensamento intuitivo, positivo e criativo. Essa informação nos leva a formular algumas questões: "Que produto/serviço diferenciado pode-se apresentar nesse segmento de mercado? $O$ que poderia ser um diferencial e mais específico nesse setor?” Conhecer o cliente potencial é a chave, lembrando que ele é um ser que se relaciona e que possui necessidades e requisitos.

No Brasil, o SEBRAE tem sido considerado o órgão responsável por implantar a cultura do empreendedorismo, quer seja nas universidades, quer seja no mercado como um todo, com o intuito de orientar os pequenos empresários no momento da abertura de seus negócios e no desempenho de suas atividades, proporcionando uma compreensão ao brasileiro sobre como introduzir um plano de negócios em seu empreendimento, a fim de geri-lo, de modo a gerar um fluxo de receitas constante e autônomo, visando à sustentação a 
médio e longo prazo. Consequentemente tendo uma oportunidade de analisar o mercado que está inserida, através das estratégias adotadas elaboradas no direcionamento do plano de negócios e visar uma possível expansão, aplicando certos métodos de mercado. Portanto, estimular modelos para o desenvolvimento da economia brasileira.

Com a crise econômica, muitos brasileiros tiveram a conveniência de começar seu próprio negócio, no entanto, muitos não se prepararam de forma adequada para esse momento, e deixam certas lacunas que podem provocar o interesse de novos entrantes nesse mercado, área onde se pretende focar por essa imprudência, que se observa que esses novos atuantes deixam em evidência, por falta de uma qualificação e certa falta de destreza nesse nicho, tendo certo impacto em seu micro negócio, limitando de um crescimento nessa área de atuação. Isso acontece em parte porque os especialistas estão dispostos a habilitar a maioria dos leigos em relação a essa metodologia, no entanto, poucas pessoas interessadas nessa área, buscam habilitar esse conhecimento. Mas, ultimamente está começando a mudar com adjunto da internet e certas mídias sociais, que informa de forma precisa aos leitores que tenham o mínimo de interesse no tema que certos institutos como SEBRAE e novos especialistas, estão inundando o mercado sobre esse método. Para empreender em áreas interessantes como o mercado de estética masculina.

Isso vem a ser conveniente, pois historicamente, a taxa de mortalidade dos empreendimentos gera em torno de $80 \%$ até completar o segundo ano de existência. Essa taxa caiu para 22\% sobre as empresas iniciadas em 2005 entre as empresas registradas. Não existem dados dos empreendimentos informais, mas estima-se que o índice de mortalidade destes deve ser bem maior. (SEBRAE, 2006)

Tendo em vista o contexto exposto o presente estudo tem como proposta desenvolver um Plano de Negócio com auxílio do software SEBRAE 3.0, para criação de um sistema de franquias de uma barbearia e bar temático, onde seja possível inovar o modelo de gestão atual, alavancar e promover o empreendimento no mercado estético.

\section{FUNDAMENTAÇÃO TEÓRICA}

\subsection{PLANO DE NEGÓCIOS}

Segundo Longenecker et al. (1997), o plano de negócios constitui a base para as atividades empresariais, e formaliza no papel as ideias criativas do empreendedor para atender às necessidades do público alvo por determinado produto ou serviço. Na Figura 1 a seguir, são apresentadas as etapas do Plano de Negócios.

Figura 1: Etapas do Plano de Negócios

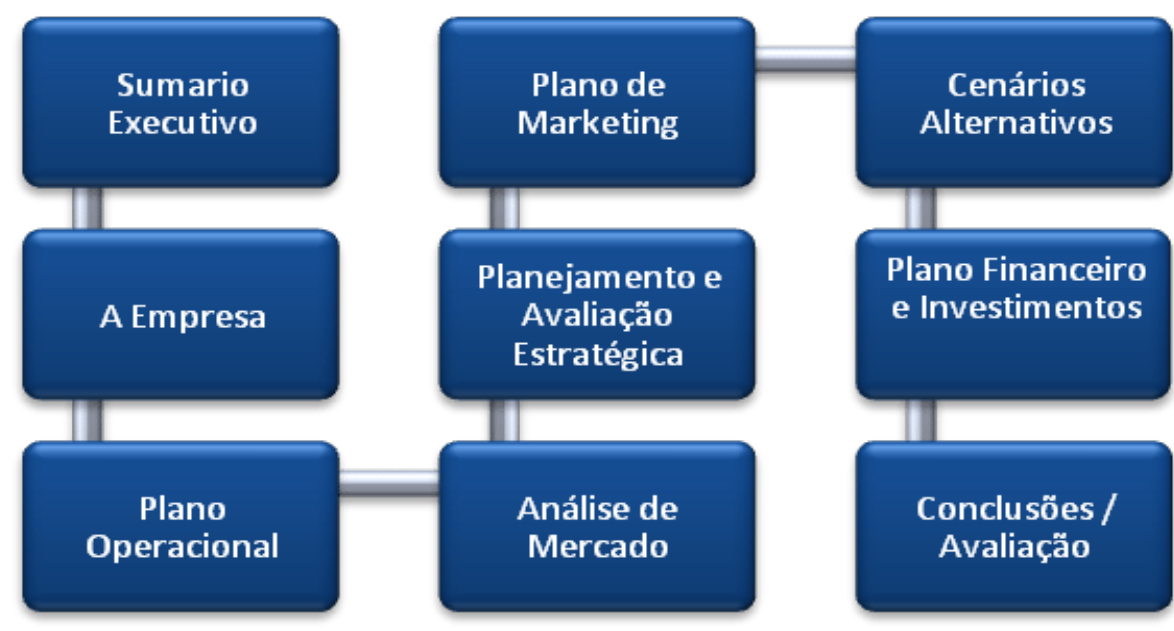




\subsection{FERRAMENTAS DE GESTÃO}

Fonte: Blog Luz (2019)

Criada por Kenneth Andrews e Roland Cristensen, professores da Harvard Business School, e posteriormente aplicadas por inúmeros acadêmicos, a análise SWOT. A Figura 2 a seguir, estuda a competitividade de uma organização segundo quatro variáveis: Strengths (Forças), Weaknesses (Fraquezas), Oportunities (Oportunidades) e Threats (Ameaças). Através destas quatro variáveis, poderá fazer-se a inventariação das forças e fraquezas da empresa, das oportunidades e ameaças do meio em que a empresa atua. (RODRIGUES et al., 2005)

Figura 2: Matriz SWOT

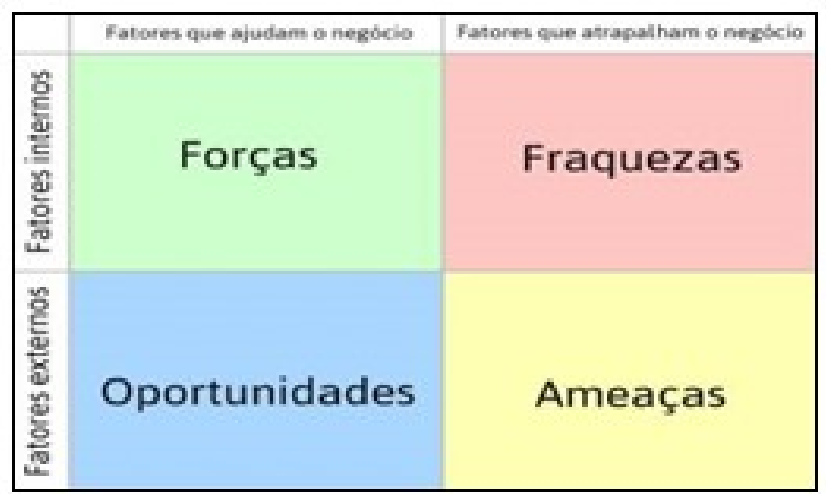

Fonte: Rodrigues et al. (2005)

Segundo Serra, Torres \& Torres (2004), a análise do ambiente externo pode ser realizada por meio do modelo de cinco forças da competitividade, desenvolvido por Michael Porter na década de 70. Afirmam ainda que o entendimento das forças rivais de um ramo de negócios é essencial para o correto desenvolvimento do plano estratégico.

Na Figura 3 a seguir, é apresentada a elaboração das cinco forças de Porter, na qual se baseia no poder de barganhar dos fornecedores, as ameaças de novos produtos, a barganha que os clientes têm sobre a empresa, ameaça de novos entrantes e a rivalidade entre os possíveis concorrentes.

Figura 3: Cinco Forças de Porter

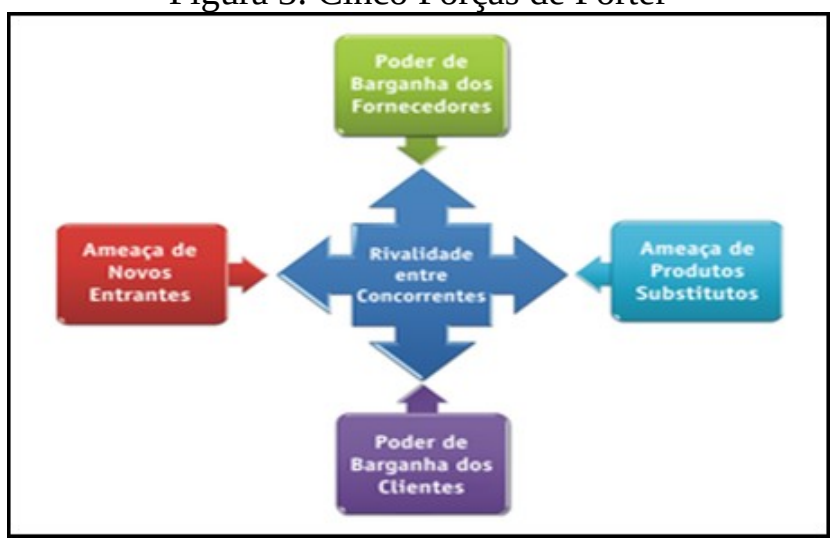

Fonte: Serra, Torres e Torres (2018)

\subsection{PLANO DE NEGÓCIO 3.0}

O Software Plano de Negócios 3.0, criado pelo SEBRAE em Minas Gerais, é uma ferramenta útil para organizar ideias e informações sobre o ramo de atividade escolhido, sobre produtos e serviços que irá oferecer clientes, concorrentes, fornecedores, pontos fortes e fracos do negócio, contribuindo para a identificação da viabilidade de sua ideia e na gestão da empresa. 


\section{METODOLOGIA}

Segundo Gil (2017) a pesquisa é “o procedimento racional e sistemático que tem como objetivo proporcionar respostas aos problemas que são propostos”.

A pesquisa é descritiva, pois foram coletados e descritos, dados referentes à performance da barbearia temática. E se torna explicativa quando se aplica a metodologia de planos de negócios e das ferramentas de gestão, analisando dados, interpretá-los e determinar as causas do fenômeno estudado.

A pesquisa é aplicada, pois foi elaborada uma proposta de melhoria em uma empresa prestadora de serviços, estudando os principais fatores para o seu atual rendimento e do serviço prestado, tais fatores foram interpretados e utilizados como base para a aplicação do plano de negócio.

Esta pesquisa é de caráter bibliográfico, pois foram utilizados diversos livros sobre o assunto em estudo como fonte de pesquisa, é documental de modo que se utilizaram os dados fornecidos pelo empreendimento e é uma pesquisa de campo, pois o autor está fazendo em conjunto com o dono do estabelecimento. Desta forma foi possível observar o fenômeno frequentemente, vivenciando o ambiente organizacional.

O universo da pesquisa foi um empreendimento privado, que atua no setor de beleza, mais especificamente na prestação de serviços de higiene e estética para o público masculino e a amostragem deste estudo é composta por um universo de 120 clientes e 4 voluntários que compõem a equipe da RD Styllos.

\section{ESTUDO DE CASO}

\subsection{A EMPRESA}

O estudo de caso foi realizado em uma empresa de prestação de serviços, localizada na cidade de Nova Iguaçu-RJ, criada com finalidade de realizar serviços no mercado estético voltado para o público masculino na Baixada Fluminense.

Por ser um empreendimento simples, o projeto proposto visa utilizar essa característica, justamente como uma vantagem competitiva no qual o proprietário visava.

A barbearia escolhida tem um tamanho razoável de aproximadamente $100 \mathrm{~m}^{2}$ interno, mais $80 \mathrm{~m}^{2}$ externo, tendo equivalente a $180 \mathrm{~m}^{2}$, sendo a área externa utilizada para eventos do empreendimento no decorrer da noite, pois as quartas, sextas e sábados ela funciona como um bar temático.

\subsection{INDICADORES DO PROJETO}

Na Tabela 1 a seguir, é apresentada os indicadores com o aporte necessário para o desenvolvimento do projeto ao longo do primeiro ano de aplicação, nele, consegue-se calcular que seu ponto de equilíbrio é orçado em $\mathrm{R} \$ 259.282,93$ tendo assim uma lucratividade razoável em seu primeiro ano de 19,60\% e uma rentabilidade considerável de $127,21 \%$, apontando para um projeto com um grande potencial, tendo seu prazo de retorno em dez meses.

Tabela 1: Indicadores

\begin{tabular}{|c|c|}
\hline Indicadores & Ano 1 \\
\hline $\begin{array}{c}\text { Ponto de } \\
\text { Equilibrio }\end{array}$ & RS259.282,93 \\
\hline Lucratividade & $19,60 \%$ \\
\hline Rentabilidade & $127,21 \%$ \\
\hline $\begin{array}{c}\text { Prazo de retomo do } \\
\text { investimento }\end{array}$ & 10 meses \\
\hline
\end{tabular}

Fonte: Autores (2019) 
A parte burocrática para fins de impostos e contribuição junto as partes envolvidas, terá a utilização de MEI (Microempreendedor Individual), além de ser atribuído uma divisão igualitária através de uma Sociedade Limitada.

Na Tabela 2 a seguir são apresentados os investimentos de cada sócio para a viabilização inicial do projeto.

Tabela 2: Investimentos de cada sócio

\begin{tabular}{|c|c|c|c|}
\hline $\mathbf{N}^{\circ}$ & Sócio & Valor & Participação (\%) \\
\hline 1 & Rodrigo Henrique Lima Lemos & RS $27.371,80$ & 50,00 \\
\hline 2 & Ricardo & RS $27.371,80$ & 50,00 \\
\hline Total & & RS 54.743,60 & $\mathbf{1 0 0 , 0 0}$ \\
\hline
\end{tabular}

Fonte: Autores (2019)

A fonte de recursos provém de um empréstimo junto a caixa econômica federal equivalente a $\mathrm{R} \$ 28.000,00$, mais um aporte de $\mathrm{R} \$ 28.000,00$ junto ao SEBRAE, após apresentação do projeto, junto ao incentivo proposto pelo governo para pequenas e microempresas.

\subsection{ANÁLISE DE MERCADO}

\subsubsection{Público Alvo}

Homens com uma faixa etária entre 4 a 55 anos, geralmente com uma escolaridade que varia entre o ensino fundamental, médio e nível superior, com uma renda entre R $\$ 980,00$ e $\mathrm{R} \$ 8.000,00$, homens que se vistam dos mais variados jeitos, mas que sempre prezam pelo seu aspecto visual, mas que busquem um preço acessível, junto a uma qualidade ao serviço e uma ótima estrutura.

\subsubsection{Concorrência}

Na Tabela 3 a seguir, os concorrentes citados oferecem de uma boa infraestrutura, sendo considerados os melhores da região, todos oferecem basicamente os mesmos serviços, com pouca diferença nos preços ofertados, algo que dentro do nosso planejamento estamos dispostos a mudar em busca de um diferencial.

Tabela 3: Principais concorrentes

\begin{tabular}{|c|c|c|c|c|c|c|}
\hline Empresa & Qualidade & Preço & $\begin{array}{c}\text { Condiçöes de } \\
\text { Pagamento }\end{array}$ & Localização & Atendimento & Serviços aos clientes \\
\hline Confraria da Barba & $\begin{array}{l}\text { Segundo as pesquisas } \\
\text { de qualidade oferecida } \\
\text { em seu site, a } \\
\text { classificação dos } \\
\text { clientes que pode } \\
\text { contar com uma } \\
\text { aferição de ótimo a } \\
\text { pésimo atendimento, } \\
\text { oferece um serviço de } \\
\text { ótima qualidade. }\end{array}$ & RS 35,00 a R\$ 80,00 & \begin{tabular}{|l|} 
Crédito \\
Débito \\
Espécie
\end{tabular} & $\begin{array}{l}\text { Av. Dr. Mario } \\
\text { Guimarães, } 839 \text { - } \\
\text { Centro, Nova Iguaçu - } \\
\text { RJ }\end{array}$ & $10: 00$ as $21: 00$ & \begin{tabular}{|l} 
Cabelo \\
Barba \\
Quimica capilar \\
Massagem \\
Podologia \\
Depilação \\
Bar \\
Sinuca \\
Dia do Noivo \\
Poker \\
Games \\
\end{tabular} \\
\hline Gallo & $\begin{array}{l}\text { Segundo as pesquisas } \\
\text { de qualidade oferecida } \\
\text { em seu site, a } \\
\text { classificação dos } \\
\text { clientes que pode } \\
\text { contar com uma } \\
\text { aferição de ótimo a } \\
\text { pésimo atendimento, } \\
\text { oferece um serviço de } \\
\text { ótima qualidade. }\end{array}$ & RS 20,00 a R\$ 70,00 & $\begin{array}{l}\text { Crédito } \\
\text { Débito } \\
\text { Espécie }\end{array}$ & $\begin{array}{l}\text { Rua Getúlio Vargas, } \\
121 \text { - Loja E - Centro, } \\
\text { Nova Iguaçu - RJ }\end{array}$ & $09: 00$ as $21: 00$ & $\begin{array}{l}\text { Corte de cabelo } \\
\text { Barba } \\
\text { Cerveja } \\
\text { Bigode } \\
\text { Pé do cabelo } \\
\text { Sobrancelha } \\
\text { Alinhamento } \\
\text { Hidratação } \\
\text { Após as 21:00 } \\
\text { somente bar } \\
\end{array}$ \\
\hline Don Juan & $\begin{array}{l}\text { De acordo com a } \\
\text { escala de ótimo a ruim } \\
\text { em seu site e redes } \\
\text { sociais, a maioria dos } \\
\text { clientes a classificaram } \\
\text { como ótimo, sendo } \\
\text { referência na baixada } \\
\text { fluminense. }\end{array}$ & RS 10,00 ás RS 70,00 & $\begin{array}{l}\text { Crédito } \\
\text { Débito } \\
\text { Espécie }\end{array}$ & $\begin{array}{l}\text { Vitality Center - Av. Dr. } \\
\text { Mario Guimarâes, 318 } \\
\text { - loja } 5 \text { - Centro, Nova } \\
\text { Iguaçu - RJ }\end{array}$ & $10: 00$ ás $22: 00$ & $\begin{array}{l}\text { Corte } \\
\text { Barba } \\
\text { Corte mais barba } \\
\text { Pé do cabelo } \\
\text { Sobrancelha }\end{array}$ \\
\hline $\begin{array}{l}\text { Barbearia Los } \\
\text { Barbaros }\end{array}$ & $\begin{array}{l}\text { Segundo as pesquisas } \\
\text { de qualidade nas redes } \\
\text { sociais como } \\
\text { Facebook e Instagram, } \\
\text { com uma aferição de } \\
\text { ótimo a péssimo } \\
\text { atendimento, oferece } \\
\text { um serviço de ótima } \\
\text { qualidade de acordo } \\
\text { com seus clientes. }\end{array}$ & RS 20,00 a R\$ 70,00 & \begin{tabular}{|l} 
Crédito \\
Débito \\
Espécie
\end{tabular} & $\begin{array}{l}\text { R...Guatemala, } 86 \text { - } \\
\text { Rancho Novo, Nova } \\
\text { lguaçu - RJ }\end{array}$ & 10:00 ás 21:00 & $\begin{array}{l}\text { Cabelo } \\
\text { Barba } \\
\text { Cabelo mais barba } \\
\text { Pé do cabelo } \\
\text { Cerveja } \\
\text { Sinuca } \\
\text { Dia do noivo } \\
\text { Games }\end{array}$ \\
\hline
\end{tabular}

Fonte: Autores (2019) 


\subsubsection{Fornecedores}

$\mathrm{Na}$ Tabela 4 a seguir, foram analisados todos os fornecedores envolvidos na aplicação dessa proposta de projeto, com precificação, condições de pagamento, prazo de entrega e localização deles.

Tabela 4: Fornecedores do Empreendimento

\begin{tabular}{|c|c|c|c|c|c|c|}
\hline $\mathbf{N}^{\circ}$ & $\begin{array}{c}\text { Descrição dos itens a } \\
\text { serem adquiridos } \\
\text { (matérias-primas, } \\
\text { insumos, mercadorias } \\
\text { e serviços) }\end{array}$ & Nome do fornecedor & Preço & $\begin{array}{l}\text { Condiçöes de } \\
\text { pagamento }\end{array}$ & Prazo de entrega & $\begin{array}{l}\text { Localização (estado } \\
\text { e/ou municipio) }\end{array}$ \\
\hline 1 & $\begin{array}{l}3 \text { Máquinas de Cortar } \\
\text { Cabelo Wahl Home Cut } \\
\text { Basic } \\
3 \text { Máquinas de Corte de } \\
\text { Cabelo Wahl Clipper } \\
\text { Quickcut Branca - 9W } \\
3 \text { Máquinas de Aparar } \\
\text { Pelos T-Pro Bivolt - } \\
\text { Wahl Clipper } \\
\text { 3 Aparadores de Barba } \\
\text { e Pêlos Groomsman } \\
\text { Recarregável Bivolt } \\
\text { REC - Wahl Clipper } \\
\end{array}$ & Wahl & $\begin{array}{l}\text { RS } 195,00 \\
\text { Rs } 357,00 \\
\text { Rs } 216,00 \\
\text { RS } 359,00\end{array}$ & $\begin{array}{l}\text { Crédito } \\
\text { Débito } \\
\text { Tranferência(boleto) }\end{array}$ & $\begin{array}{l}\text { Entrega em até duas } \\
\text { semanas. }\end{array}$ & $\begin{array}{l}\text { Galpão } 45 \text { Califórnia } \\
\text { Centre Rodovia Geraldo } \\
\text { Scavone, } 2300 \text { Jardim } \\
\text { Califómia Jacarei SP } \\
12305-490 \text { BR, Rod. } \\
\text { Geraldo Scavone, } 2300 \\
\text { - Jardim California, São } \\
\text { José dos Campos - SP, } \\
12305-490\end{array}$ \\
\hline 2 & $\begin{array}{l}4 \text { Cadeiras Poltrona } \\
\text { Cabelereiro Reclinável }\end{array}$ & Lumi Móveis & RS $4.400,00$ & $\begin{array}{l}\text { Crédito } \\
\text { Débito } \\
\text { Espécie } \\
\text { Transferência }\end{array}$ & Cerca de 3 semanas & $\begin{array}{l}\text { Rua Gonçalves Gato, } \\
380 \\
\text { Vila Dagmar - Belford } \\
\text { Roxo - RJ }\end{array}$ \\
\hline \multirow[t]{2}{*}{3} & $\begin{array}{l}\text { Navalhete Sekich } \\
\text { Recarregável }\end{array}$ & Olist & RS 08,00 & Crédito & $\begin{array}{l}\text { Duas semanas de } \\
\text { entrega }\end{array}$ & $\begin{array}{l}\text { Rua Andréa Paulinetti, } \\
281 \text { - São Paulo / SP }\end{array}$ \\
\hline & $\begin{array}{l}2 \text { Tesouras Profissional } \\
\text { Cabeleireiros } 6 \text { Pol. } \\
\text { Espanador } \\
\text { Pentes }\end{array}$ & & $\begin{array}{l}\text { RS } 37,90 \\
\text { RS 35,00 } \\
\text { RS } 18,00\end{array}$ & $\begin{array}{l}\text { Débito } \\
\text { Trânsferência }\end{array}$ & & \\
\hline 4 & $\begin{array}{l}\text { Capa personalizada } \\
\text { Avental personalizado }\end{array}$ & L.R. acessórios & $\begin{array}{l}\text { RS } 35,00 \\
\text { RS } 75,00\end{array}$ & $\begin{array}{l}\text { Crédito } \\
\text { Débito }\end{array}$ & Duas semanas & $\begin{array}{l}\text { R. Santana do Garambu } \\
-288 \text {, são Paulo }\end{array}$ \\
\hline 5 & Lâminas & Lord & RS 100,00 & $\begin{array}{l}\text { Crédito } \\
\text { Débito }\end{array}$ & Duas semanas & Lojas de atacado \\
\hline 6 & Produtos de beleza & Embeleze & Até R\$ 120,00 & $\begin{array}{l}\text { Crédito } \\
\text { Débito }\end{array}$ & Até quatro dias & $\begin{array}{l}\text { Av. Mal, Floriano } \\
\text { Peixoto, } 1784,- \text { Centro, } \\
\text { Nova Iguaçu - RJ, } \\
26210-000 \\
\end{array}$ \\
\hline 7 & $\begin{array}{l}\text { Fornecimentos de } \\
\text { suprimentos } \\
\text { - Cervejas } \\
\text { - Refrigerantes } \\
\end{array}$ & Amber & $\begin{array}{l}\text { RS } 3.000,00 \\
\text { RS } 2.000,00\end{array}$ & $\begin{array}{l}\text { Crédito } \\
\text { Débito } \\
\text { Transferência } \\
\text { Espécie }\end{array}$ & $\begin{array}{l}\text { Entrega geralmente em } \\
\text { um dia. }\end{array}$ & $\begin{array}{l}\text { R. Áurea Fonseca de } \\
\text { Jesus, } 280 \text { - Califórnia, } \\
\text { Nova Iguaçu - RJ, } \\
26220-120\end{array}$ \\
\hline 8 & Fornecedora alimenticia & Top Alto Alimentos & Rs $5.000,00$ & $\begin{array}{l}\text { Crédito } \\
\text { Débito }\end{array}$ & $\begin{array}{l}\text { Entrega durante } \circ \\
\text { período de } 24 \text { horas }\end{array}$ & $\begin{array}{l}\text { R. São João Batista, } 99 \\
\text { - Jardim Jose Bonifacio, } \\
\text { São João de Meriti - RJ, } \\
25515-420\end{array}$ \\
\hline 9 & $\begin{array}{l}\text { Fogões industriais } \\
\text { Utesillios para cozinha }\end{array}$ & Udan & RS $4.000,00$ & $\begin{array}{l}\text { Crédito } \\
\text { Débito } \\
\text { Transferência }\end{array}$ & $\begin{array}{l}\text { Entrega em até uma } \\
\text { semana }\end{array}$ & $\begin{array}{l}\text { Araçatuba, } 38, \text { fds, } \\
\text { Jardim Bela Vista, } \\
\text { Catanduva, SP, } 15806- \\
335\end{array}$ \\
\hline
\end{tabular}

Fonte: Autores (2019)

\subsection{PLANO DE MARKETING}

Pretende-se prestar um serviço com qualidade semelhante às principais concorrentes, com infraestrutura impecável, porém com um preço abaixo do preço de mercado, a fim de se inserir num nicho com poder aquisitivo mais baixo, mas que utiliza esse tipo de serviço.

Na Tabela 5 a seguir, demonstra os preços dos produtos ofertados de acordo com o projeto proposto. 
Tabela 5: Serviços e preços

\begin{tabular}{|c|}
\hline Preços para corte de cabelo popular de RS 12,00 \\
\hline Preços para fazer a barba de RS O8,00 \\
\hline Preços para corte mais barba de RS 18,00 \\
\hline Preços para o pé do cabelo RS 05,00 \\
\hline Preços para sobrancelha RS 5,00 \\
\hline Preços para o serviço geral RS 22,00 \\
\hline Preços para a cerveja RS 5,00 \\
\hline Preços para drinks RS O5,O0 a RS 20,00 \\
\hline Preços para comidas e petiscos RS 15,00 a RS \\
\hline Preços para o refrigerante RS 4,00 \\
\hline Preços para acessórios RS 15,00 \\
\hline Preços para produtos de beleza RS 20,00 \\
\hline
\end{tabular}

Fonte: Autores (2019)

Divulgação será realizada através de entrega de panfletos, banners e Outdoors nas ruas e bairros próximos ao empreendimento.

Mídias sociais também serão bastante utilizadas como Instagram e Facebook para ampliar a abrangência e alcance sobre o público que se busca laçar, com divulgação através de blogueiros com mais de 5 mil seguidores, divulgação ampla através de jovens proeminentes.

\subsection{PLANO OPERACIONAL}

Inicialmente serão aplicadas as atribuições de um plano estratégico a fim de diminuir os custos operacionais, com uma limitação no número de funcionário, mas com uma ótima infraestrutura, algo que é precário na maioria das barbearias mais populares, aplicar parcerias cirúrgicas com fornecedores em produtos e utensílios, otimizando os gastos.

Negociar um acordo com barbeiros locais em médio prazo, fundindo suas operações com o projeto proposto, gerando um cinturão com grande alcance de expansão da marca na região, aplicar o plano de negócio elaborado pela gestão responsável pelo projeto aplicando o modelo proposto, junto aos novos parceiros, com os seguintes modelos.

- Com três barbeiros e um assistente.

- Oferecer serviços de cortes diferenciados.

- Serviços paralelos como cervejas e jogos.

- Em dias de bar, serviços com comidas, bebidas.

\subsection{PLANO FINANCEIRO}

Na Tabela 6 a seguir é apresentado o plano financeiro, onde é aplicado todo o investimento fixo feito no empreendimento, observa-se a soma do gasto aplicado às máquinas, móveis e utensílios. 
Tabela 6: Gastos com equipamentos

\begin{tabular}{|c|c|c|c|c|}
\hline \multicolumn{5}{|c|}{ A-Imóveis } \\
\hline$x$ & Descrisalo & Qude & Valor Unitsrio & Total \\
\hline \multicolumn{4}{|c|}{ SUB-TOTAL (A) } & FS 0,00 \\
\hline \multicolumn{5}{|c|}{ B- Mláquinas } \\
\hline $\mathrm{N}^{*}$ & Descrixise & Qode & Valor Unitirio & Total \\
\hline 1 & Video Games & 2 & RS $3,000,00$ & RS $6,000,00$ \\
\hline 2 & Maguinas Wahl & 3 & RS 255,00 & RS 765,00 \\
\hline 3 & $\begin{array}{l}\text { Senart TV LED 32- HD } \\
\text { Samsome }\end{array}$ & 3 & RS 1.02900 & RS $3,087,00$ \\
\hline 4 & Foglo Induatrial 6 bocas & 1 & RS 1.469 .99 & RS $1.469,99$ \\
\hline \multicolumn{4}{|c|}{ SUR-TOTAL (B) } & RS $11.324,99$ \\
\hline \multicolumn{5}{|c|}{$C-$ Equipamentos } \\
\hline$x=$ & Descrixiso & Qode & Valor Vnitario & Total \\
\hline \multicolumn{4}{|c|}{ SUR-TOTAICO } & RS 0,00 \\
\hline \multicolumn{5}{|c|}{ D - Móveis e Utensílios } \\
\hline $\mathrm{x}^{*}$ & Descrixiso & Qode & Valor Unitiorio & Total \\
\hline 1 & Capa e Avental & 3 & RS 110,00 & RS 330,00 \\
\hline 2 & Utensalios & 3 & RS 382,00 & RS $1.1=6,00$ \\
\hline 3 & Potrrona Rectinswel & 3 & RS $1.100,00$ & $253.300,00$ \\
\hline 4 & $\begin{array}{c}\text { Ar Condiebeesdo Splix Hi Wiall } \\
\text { Electrolex }\end{array}$ & 2 & RS 1.043 .10 & RS 2.086 .20 \\
\hline 5 & Tonó Elíne - Pteto & 1 & RS $1.296,04$ & RS $1.296,04$ \\
\hline 6 & Utensilios de corrinha & 1 & RS 2,530,00 & RS $2.530,00$ \\
\hline \multicolumn{4}{|c|}{ SUB-TOTAL (D) } & RS $10.685,24$ \\
\hline \multicolumn{5}{|c|}{ E - Veiculos } \\
\hline $\mathbf{s}^{*}$ & Descricata & Qede & Valor Unitaribo & Total \\
\hline \multicolumn{4}{|c|}{ SUB-TOTAL (E) } & RS 0,00 \\
\hline \multicolumn{5}{|c|}{ F - Computadores } \\
\hline$x$ & Descrificlo & Qode & Vabor Enitirio & Total \\
\hline \multicolumn{4}{|c|}{ SUB-TOTAL (F) } & RES 0,00 \\
\hline \multicolumn{5}{|c|}{ TOTAL DOS NVVESTIMENTOS FIXOS } \\
\hline \multicolumn{4}{|c|}{$\begin{array}{l}\text { TOTAL DOS INESTMMENTOS FIXOS } \\
\qquad(A+B+C+D+E+F)=\end{array}$} & RS $22.013,23$ \\
\hline
\end{tabular}

Fonte: Autores (2019)

No estoque inicial na Tabela 7, se tem o capital de giro investido mensalmente por parte dos dois sócios envolvidos no negócio, no qual, se aplica um dinheiro em prol das necessidades mensais do projeto.

Tabela 7: Circulação do capital de giro

\begin{tabular}{|c|c|c|c|c|}
\hline $\mathbf{N}^{\circ}$ & Descrição & Qtde & Valor Unitário & Total \\
\hline 1 & Dinheiro em circulação & 2 & RS $5.000,00$ & RS $10.000,00$ \\
\hline $\begin{array}{c}\text { TOTAL } \\
\text { (A) }\end{array}$ & & RS 10.000,00 \\
\hline
\end{tabular}

Fonte: Autores (2019)

Na Tabela 8, o caixa mínimo tem o prazo médio de vendas, onde se configura o tempo médio para a entrada de caixa dos serviços prestados, em seguida prazo médio de compras, onde o empreendimento tem uma média de fluxo de estoque junto aos fornecedores, onde se obtém uma necessidade média de 30 dias de ter estoque armazenado. No seguinte, é analisado o cálculo para aplicar o capital de gira, no qual teve um número satisfatório de 45 dias de aplicação do mesmo, tendo um caixa mínimo de $\mathrm{R} \$ 11.508,37$ para aplicação, sendo realista e positivo no cenário previsto, obtendo um capital de giro mínimo de $\mathrm{R} \$ 21.580,37$ no início do projeto, podendo ser amortizado ao longo da aplicação do projeto. 
Tabela 8: Necessidades e capital de giro

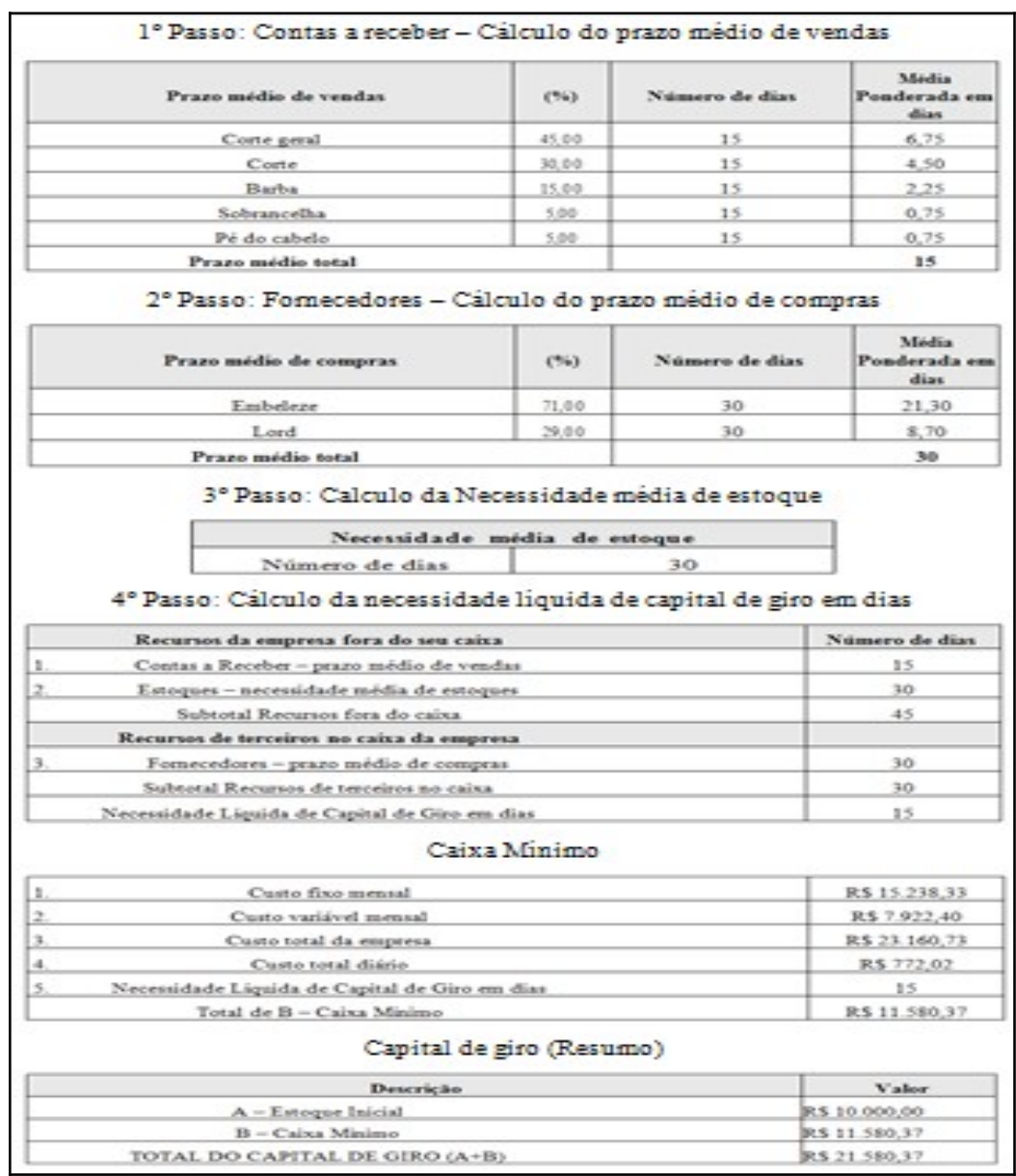

Fonte: Autores (2019)

Na Tabela 9, o investimento para o desenvolvimento do projeto matriz, com todos os gastos com despesas, obras, divulgação, além de outras despesas.

Tabela 9: Investimento para início do projeto

\begin{tabular}{|c|c|}
\hline Descrição & Valor \\
\hline Despesas de Legalização & RS 150,00 \\
\hline Obras civis e/ou reformas & RS $5.000,00$ \\
\hline Divulgação de Lançamento & RS $2.000,00$ \\
\hline Cursose Treinamentos & RS 0,00 \\
\hline Outras desnesas & RS 4000,00 \\
\hline TOTAL & RS $11.150,00$ \\
\hline
\end{tabular}

Fonte: Autores (2019)

No Gráfico 1, de setores onde mostra a divisão dos investimentos fixos, capital de giro e investimentos pré-operacionais. 
Gráfico 1: Gráfico de setores dos investimentos iniciais

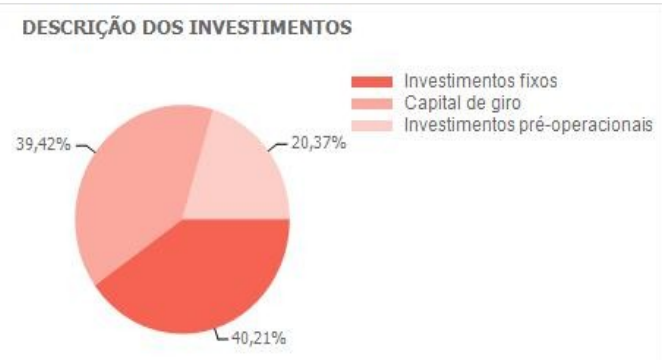

Fonte: Autores (2019)

Na Tabela 10, percebe-se o investimento de recursos próprios, de terceiros e sua divisão, deixando mais evidente sua importância para o empreendimento.

Tabela 10: Investimento total

\begin{tabular}{|c|c|c|}
\hline Fontes de recursos & Valor & (\%) \\
\hline Recursos próprios & RS $27.371,80$ & 50,00 \\
\hline Recursos de terceiros & RS $27.371,80$ & 50,00 \\
\hline Outros & RS 0,00 & 0,00 \\
\hline TOTAL $(\mathbf{1}+\mathbf{2}+\mathbf{3})$ & RS 54.743,60 & $\mathbf{1 0 0 , 0 0}$ \\
\hline
\end{tabular}

Fonte: Autores (2019)

Na Tabela 11, a empresa apresenta todos os serviços ofertados com os preços estabelecidos para eles de forma unitária, organizando e demonstrando um faturamento de forma mensal.

Tabela 11: Receita mensal

\begin{tabular}{|c|c|c|c|c|}
\hline $\mathbf{N}^{\circ}$ & Produto/Serviço & $\begin{array}{c}\text { Quantidade } \\
\text { (Estimativa de } \\
\text { Vendas) }\end{array}$ & $\begin{array}{c}\text { Preço de } \\
\text { Venda } \\
\text { Unitário } \\
\text { (em RS) }\end{array}$ & $\begin{array}{c}\text { Faturamento Total } \\
\text { (em RS) }\end{array}$ \\
\hline 1 & Corte total & 320 & RS 22,00 & RS $7.040,00$ \\
\hline 2 & Cabelo & 295 & RS 12,00 & RS $3.540,00$ \\
\hline 3 & Barba & 212 & RS 8,00 & RS $1.696,00$ \\
\hline 4 & Sobrancelha & 90 & RS 5,00 & RS 450,00 \\
\hline 5 & Pé do Cabelo & 90 & RS 5,00 & RS 450,00 \\
\hline 6 & Cremes & 55 & RS 20,00 & RS $1.100,00$ \\
\hline 7 & Pentes, pulseiras & 30 & RS 15,00 & RS 450,00 \\
\hline 8 & Cerveja & 845 & RS 5,00 & RS $4.225,00$ \\
\hline 9 & Refrigerante & 620 & $\mathrm{RS} 4,00$ & RS $2.480,00$ \\
\hline 10 & Cabelo mais barba & 250 & RS 18,00 & RS $4.500,00$ \\
\hline 11 & Comidas e petiscos & 115 & RS 25,00 & RS $2.875,00$ \\
\hline \multicolumn{4}{|c|}{ TOTAL } & RS $28.806,00$ \\
\hline
\end{tabular}

Fonte: Autores (2019)

Na MD (material direto), e MV (material vendido) têm os custos dos serviços prestados de forma unitária, calculando o gasto com cada serviço chegando ao gasto médio de R\$5.041,00 ao mês, como pode-se observar na Tabela 12 a seguir. 
Tabela 12: Custos dos serviços

\begin{tabular}{|c|c|c|c|c|}
\hline $\mathbf{N}^{\circ}$ & Produto/Serviço & $\begin{array}{c}\text { Estimativa de } \\
\text { Vendas (em } \\
\text { unidades) }\end{array}$ & $\begin{array}{c}\text { Custo Unitário } \\
\text { de Matériais } \\
\text { /Aquisições }\end{array}$ & $\mathbf{C M D} / \mathbf{C M V}$ \\
\hline 1 & Corte total & 320 & RS 0,40 & RS 128,00 \\
\hline 2 & Cabelo & 295 & RS 0,40 & RS 118,00 \\
\hline 3 & Barba & 212 & RS 0,40 & RS 84,80 \\
\hline 4 & Sobrancelha & 90 & RS 0,20 & RS 18,00 \\
\hline 5 & Pé do Cabelo & 90 & RS 0,20 & RS 18,00 \\
\hline 6 & Cremes & 55 & RS 10,00 & RS 550,00 \\
\hline 7 & Pentes, pulseiras & 30 & RS 7,50 & RS 225,00 \\
\hline 8 & Cerveja & 845 & RS 2,00 & RS $1.690,00$ \\
\hline 9 & Refrigerante & 620 & RS 2,00 & RS $1.240,00$ \\
\hline 10 & Cabelo mais barba & 250 & RS 0,20 & RS 50,00 \\
\hline 11 & Comidas e petiscos & 115 & RS 8,00 & RS 920,00 \\
\hline \multicolumn{3}{|l|}{ TOTAL } & & RS 5.041,80 \\
\hline
\end{tabular}

Fonte: Autores (2019)

A seguir na Tabela 13 a seguir, é inserido cada mão de obra necessária e seus gastos, com inclusão dos encargos sociais, seus salários e todo montante que será gerado.

Tabela 13: Custos mão de obra

\begin{tabular}{|c|c|c|c|c|c|c|}
\hline Função & $\begin{array}{c}\mathbf{N}^{\circ} \text { de } \\
\text { Empregados }\end{array}$ & $\begin{array}{c}\text { Salário } \\
\text { Mensal }\end{array}$ & Subtotal & $\begin{array}{c}\text { (\%) } \\
\text { de } \\
\text { Encargos } \\
\text { sociais }\end{array}$ & $\begin{array}{l}\text { Encargos } \\
\text { sociais }\end{array}$ & Total \\
\hline $\begin{array}{c}\text { Auxiliar de } \\
\text { barbeiro }\end{array}$ & 1 & RS $1.200,95$ & RS $1.200,95$ & 25,00 & RS 300,24 & RS $1.501,19$ \\
\hline Barbeiros & 3 & RS $1.801,44$ & RS $5.404,32$ & 25,00 & RS $1.351,08$ & RS $6.755,40$ \\
\hline Terceirizada & 1 & RS $3.500,00$ & RS $3.500,00$ & 0,00 & RS 0,00 & RS $3.500,00$ \\
\hline TOTAL & $\mathbf{5}$ & & $\mathbf{1 0 . 1 0 5 , 2 7}$ & & RS 1.651,32 & RS $\mathbf{1 1 . 7 5 6 , 5 9}$ \\
\hline
\end{tabular}

Fonte: Autores (2019)

Na Tabela 14 a seguir, aplicasse os custos com depreciação no qual os produtos sofreram ao decorrer do tempo, sendo incluído como despesa no decorrer de sua vida útil. Uma fórmula feita para se ter projeção de troca dos mesmos

Tabela 14: Depreciação dos equipamentos

\begin{tabular}{|l|r|r|r|r|}
\hline \multicolumn{1}{|c|}{$\begin{array}{l}\text { Ativos } \\
\text { Fixos }\end{array}$} & Valor do bem & $\begin{array}{r}\text { Vida útil em } \\
\text { Anos }\end{array}$ & $\begin{array}{r}\text { Depreciação } \\
\text { Anual }\end{array}$ & $\begin{array}{r}\text { Depreciação } \\
\text { Mensal }\end{array}$ \\
\hline $\begin{array}{l}\text { MAQUINASE } \\
\text { EQUIPAMEN } \\
\text { TOS }\end{array}$ & RS $11.324,99$ & 1,60 & RS $7.078,12$ & RS 589,84 \\
\hline MOVEIS E & RS $10.688,24$ & 3,00 & RS $3.562,75$ & RS 296,90 \\
UTENSILIOS & & $\begin{array}{c}\text { RS } \\
\mathbf{1 0 . 6 4 0 , 8 7}\end{array}$ & RS 886,74 \\
\hline
\end{tabular}

Fonte: Autores (2019)

A seguir, na Tabela 15 a seguir, apresenta os custos fixos mensais, com o intuito de organizar os gastos e se planejar a fim de evitar surpresas. 
Tabela 15: Custos fixos mensais tabelados

\begin{tabular}{|l|r|}
\hline \multicolumn{1}{|c|}{ Descrição } & \multicolumn{1}{|c|}{ Custo } \\
\hline Aluguel & $\mathrm{R} \$ 800,00$ \\
\hline Condomínio & $\mathrm{R} \$ 0,00$ \\
\hline IPTU & $\mathrm{R} \$ 90,00$ \\
\hline Energia elétrica & $\mathrm{R} \$ 1.050,00$ \\
\hline Telefone + internet & $\mathrm{R} \$ 105,00$ \\
\hline Honorários do contador & $\mathrm{R} \$ 0,00$ \\
\hline Pró-labore & $\mathrm{R} \$ 0,00$ \\
\hline Manutenção dos equipamentos & $\mathrm{R} \$ 250,00$ \\
\hline Salários + encargos & $\mathrm{R} \$ 11.756,59$ \\
\hline Material de limpeza & $\mathrm{R} \$ 150,00$ \\
\hline Material de escritório & $\mathrm{R} \$ 0,00$ \\
\hline Taxas diversas & $\mathrm{R} \$ 0,00$ \\
\hline Serviçcos de terceiros & $\mathrm{R} \$ 150,00$ \\
\hline Depreciação & $\mathrm{R} \$ 886,74$ \\
\hline Contribuição do Microempreendedor Individual - MEl & $\mathrm{R} \$ 0,00$ \\
\hline Outras taxas & $\mathrm{R} \$ 0,00$ \\
\hline TOTAL & $\mathrm{RS} 15.238,33$ \\
\hline
\end{tabular}

Fonte: Autores (2019)

Na Tabela 16 a seguir, tem a tabela com a viabilidade do empreendimento de forma comprovado como citada na Tabela 1 de indicadores do projeto.

Tabela 16: Indicadores

\begin{tabular}{|c|c|}
\hline Indicadores & Ano 1 \\
\hline Ponto de Equilíbrio & RS 259.282,93 \\
\hline Lucratividade & $19,60 \%$ \\
\hline Rentabilidade & $127,21 \%$ \\
\hline $\begin{array}{c}\text { Prazo de retorno do } \\
\text { investimento }\end{array}$ & 10 meses \\
\hline
\end{tabular}

Fonte: Autores (2019)

\subsection{AÇÕES PREVENTIVAS E CORRETIVAS}

$\mathrm{Na}$ Tabela 17, foram feitas uma descrição de todos os cenários possíveis nessa empreitada, onde foi proposto um cenário provável que é o mais próximo possível de todo poderio financeiro desse plano de negócio, um cenário pessimista com uma dificuldade maior de se aplicar o financiamento, mas sendo viável mesmo assim, já o cenário otimista onde se tem um projeto bastante otimista e com um superávit bem acima do previsto.

Tabela 17: Cenários possíveis

\begin{tabular}{|c|c|c|c|c|c|c|}
\hline \multirow{3}{*}{ Descrį̧ăo } & \multicolumn{6}{|c|}{ Receita (pessimista) $9,95 \%$ Receita (otimista) $\quad 18,95 \%$} \\
\hline & \multicolumn{2}{|c|}{ Cenário provavel } & \multicolumn{2}{|c|}{ Cenario pessimista } & \multicolumn{2}{|c|}{ Cenario otimista } \\
\hline & Valor & $(\%)$ & valor & $(\%)$ & Valor & $(\%)$ \\
\hline 1. Receita total com vendas & $\mathrm{R} \$ 28.806,00$ & 100,00 & $R \$ 25.939,80$ & 100,00 & $R \$ 34.264,74$ & 100,00 \\
\hline \multicolumn{7}{|l|}{ 2. Custos variảveis totais } \\
\hline $2.1(-)$ Custos com materiais diretos e ou CMV & $\mathrm{R} \$ 5.041,80$ & 17,50 & $\mathrm{R} \$ 4.540,14$ & 17,50 & $\mathrm{R} \$ 5.997,22$ & 17,50 \\
\hline $2.2(-)$ Impostos sobre vendas & $\mathrm{RS} 0,00$ & 0,00 & $\mathrm{R} \$ 0,00$ & 0,00 & $R \$ 0,00$ & 0,00 \\
\hline $2.3(-)$ Gastos com vendas & $\mathrm{R} \$ 2.880,60$ & 10,00 & $\mathrm{R} \$ 2.593,98$ & 10,00 & $\mathrm{R} \$ 3.426,47$ & 10,00 \\
\hline Total de Custos Variáveis & $\mathrm{R} \$ 7.922,40$ & 27,50 & $\mathrm{R} \$ 7.134,12$ & 27,50 & $\mathrm{R} \$ 9.423,69$ & 27,50 \\
\hline 3. Margem de contribuição & $\operatorname{R} \$ 20.883,60$ & 72,50 & $\mathrm{R} \$ 18.805,68$ & 72,50 & R\$ 24.841,04 & 72,50 \\
\hline 4. (-) Custos fixos totais & RS $15.238,33$ & 52,90 & R\$ $15.238,33$ & 58,74 & R\$ $15.238,33$ & 44,47 \\
\hline Resultado Operacional & $\mathrm{R} \$ 5.645,27$ & 19,60 & $\mathrm{R} \$ 3.567,35$ & 13,75 & $R \$ 9.602,71$ & 28,03 \\
\hline
\end{tabular}

Fonte: Autores (2019) 
Consta que a empresa possivelmente irá gerar cerca de $\mathrm{R} \$ 5.645,27$ por mês de lucro, ou seja, R \$23.160,73 estará comprometido para os gastos do empreendimento em si num período de 11 meses, conseguindo pagar o projeto proposto, só tendo a partir daí um retorno viável no qual foi planejado.

Sendo analisado de um ângulo pessimista é calculado que só terá uma reserva no caixa da empresa de aproximadamente $\mathrm{R} \$ 3.567,35$ ao mês, tendo $\mathrm{R} \$ 22.372,45$ comprometidos com gastos relacionado a empresa.

No entanto, num âmbito totalmente otimista, se tem uma base com $\mathrm{R} \$ 9.602,72$ de lucro, tendo $\mathrm{R} \$ 24.662,02$ comprometidos com os gastos do empreendimento.

Outro ponto memorável para a otimização dos gastos, se baseia nas possíveis parcerias com as fornecedoras de materiais e acessórios de barbearia, além de fornecimento de material que as parceiras do grupo Ambev recebem da mesma, com intuito de auxiliar e promover ambas as marcas mutuamente.

\subsection{AVALIAÇÃO ESTRATÉGICA}

Na Tabela 18 a seguir, se tem a análise da matriz SWOT onde se correlaciona seus pontos fortes, fracos aos fatores internos e externos que influenciam no projeto, dentro de um quadro onde se aplica as forças que o empreendimento pode oferecer, mas em contrapartida também se analisa sua eventual fraqueza, sendo influente internamente na empresa, após esse cenário se segue aos possíveis fatores externos, onde é analisado as oportunidades que pode gerar durante esse processo, mas analisando quais fatores podem ameaçar o desenvolvimento do empreendimento.

Tabela 18: Matriz SWOT

\begin{tabular}{|c|c|c|}
\hline & FATORES INTERNOS & FATORES EXTERNOS \\
\hline $\begin{array}{l}\text { PONTOS } \\
\text { FORTES }\end{array}$ & $\begin{array}{l}\text { FORÇAS } \\
\text { Plano de negócios } \\
\text { Estrutura } \\
\text { Preço } \\
\text { Fornecedores } \\
\text { Organização } \\
\text { Otimização de gastos } \\
\text { Número de funcionários }\end{array}$ & $\begin{array}{l}\text { OPORTUNIDADES } \\
\text { Expansão da marca } \\
\text { Rede de franquias } \\
\text { Investidores } \\
\text { Padronização da marca }\end{array}$ \\
\hline $\begin{array}{l}\text { PONTOS } \\
\text { FRACOS }\end{array}$ & $\begin{array}{l}\text { FRAQUEZAS } \\
\text { Capital baixo } \\
\text { Pouca publicidade } \\
\text { Baixa margem de lucro(no periodo de retorno do investimeto) }\end{array}$ & \begin{tabular}{|l} 
AMEAÇAS \\
Novos entrantes \\
Concorrentes diretos \\
Concorrentes indiretos \\
Impostos inconstantes \\
Precos voláteis de insumos
\end{tabular} \\
\hline
\end{tabular}

Fonte: Autores (2019)

Na Tabela 19 a seguir, são apresentados os resultados para as 5 forças de Porte. 
Tabela 19: As 5 forças de Porter

\begin{tabular}{|c|c|}
\hline $\begin{array}{l}\text { Rivalidade entre os } \\
\text { concorrentes }\end{array}$ & $\begin{array}{l}\text { A rivalidade entre os concorrentes, que pode ser considerada a mais significativa } \\
\text { entre as cinco forças, se dá pela disputa por posições. Esta disputa ocorre em } \\
\text { função de pressões ou busca por melhores posições no mercado. Esta rivalidade } \\
\text { em busca de novos clientes é um ponto fraco do setor, pois torna o mesmo muito } \\
\text { competitivo. }\end{array}$ \\
\hline $\begin{array}{c}\text { Ameaça dos } \\
\text { Substitutos }\end{array}$ & $\begin{array}{l}\text { A clientela é fixa e só procura a concorrência caso os serviços não sejam } \\
\text { satisfatórios. Pode acontecer que o cliente prefira os serviços de corte de cabelo } \\
\text { em um salão, manicura e pedicuro em outro. O ideal é que o empreendedor } \\
\text { ofereça no seu salão qualidade e bons preços em todos os serviços disponíveis. }\end{array}$ \\
\hline $\begin{array}{c}\text { Poder dos } \\
\text { Fornecedores }\end{array}$ & $\begin{array}{l}\text { O setor tem bastante força de negociação com seus principais fornecedores de } \\
\text { produtos. Em relação aos prestadores de serviços (cabeleireiro, manicure etc.) o } \\
\text { poder de negociação é alto, cabendo aos salões de beleza ditarem as regras, } \\
\text { buscando um equilíbrio entre as partes nas negociações, equilíbrio este que } \\
\text { mantêm o mercado competitivo. }\end{array}$ \\
\hline Novos entrantes & $\begin{array}{l}\text { Não há muitas barreiras limitando a entrada de novos salões neste mercado, as } \\
\text { barreiras são sempre consideradas positivas para quem atua no setor. Entre elas } \\
\text { destacam-se: a exigência de um capital médio para entrar neste setor, pois em } \\
\text { geral elas têm custos fixos significativos que podem prejudicá-las de alcançar } \\
\text { suas metas estratégicas; o porte das concorrentes; o poder que os atuais grandes } \\
\text { influenciam o mercado. A força do nome são barreiras fortes para os novos } \\
\text { entrantes que gera um poder de diferenciação as oportunidades oferecidas. }\end{array}$ \\
\hline $\begin{array}{c}\text { Poder dos } \\
\text { compradores }\end{array}$ & $\begin{array}{l}\text { O poder de barganha dos clientes não representa uma preocupação para os salões, } \\
\text { pois as regras de preço são ditadas por eles. A renda dos clientes representa um } \\
\text { fator positivo ao setor, pois uma grande maioria de pessoas tem condições de } \\
\text { utilizar todos os serviços disponíveis na empresa. }\end{array}$ \\
\hline
\end{tabular}

Fonte: Autores (2019)

\section{CONSIDERAÇÕES FINAIS}

O modelo aplicado junto ao software SEBRAE 3.0 foi satisfatório, pois se conseguiu analisar questões que dificilmente seriam constatadas, todas as bases que fortalecem o projeto e possíveis vulnerabilidades que foi observada ao decorrer de toda a analise avaliaram-se uma o mercado de forma meticulosa com intuito de saber o posicionamento da empresa abordada e foi executado um plano de marketing para alinhar a RD Styllos perante a política estabelecida em nosso plano operacional, com objetivo de otimizar o máximo de gastos possíveis, incluindo até a utilização de terceirizadas para a conclusão do objetivo, até a implementação de seu logo e nova nomeação.

A aplicação das ferramentas de gestão, tiveram uma satisfação além da expectativa, com toda implementação estratégica, de marketing e do plano de ação que se pode elaborar a partir da mesma, podendo analisar todos os setores que precisam de um ajuste junto ao projeto proposto. Já a análise de SWOT conseguiu focar as áreas mais sensíveis do empreendimento em si, e seu plano de expansão, onde conseguiu ter uma orientação de suas 
forças, no qual, foi obtido também suas fraquezas, oportunidades e ameaças, sendo aplicado medidas de prevenção e estratégicas para corrigir todos os pontos em questão. Pensando nisso, foi aplicada outra ferramenta com intuito de ser mais cirúrgica, as cinco forças de Porter, onde foi analisado a rivalidade entre os concorrentes, ameaça dos substitutos, poder dos fornecedores, novos entrantes e poder dos compradores, sendo meticulosamente planejado para não ter surpresas futuras e chegando num modelo ideal, para alinhar as ideias inicias propostas no início desse estudo de caso, não só viabilizando todo projeto, como indo além da expectativa.

\section{REFERÊNCIAS BIBLIOGRÁFICAS}

DORNELAS, José Carlos Assis. Empreendedorismo: Transformando Ideias em

Negócios. 5. ed. Rio de Janeiro: Ltc, 2013. 267 p. José Carlos Assis Dornelas. 2008.

FILION, L. J. From Entrepreneurship to Entreprenology. Usasbe conference.

Proceedings, 1997.

GIL, Antônio Carlos. Como elaborar projetos de pesquisa. 6. ed. São Paulo: Atlas, 2017. $192 \mathrm{p}$.

LONGENECKER, G. J.; MOORE, C. W; PETTY, J. W. Administração de Pequenas

Empresas. São Paulo: Makron Books, 1997.

RODRIGUES, Jorge Nascimento; et al. 50 Gurus Para o Século XXI. 1. ed. Lisboa: Centro Atlântico.PT, 2005.

SEBRAE. Plano de Negócios 3.0: Referencia plano de negócios 3.0. 2012. Disponível em: $<$ http://www.sebrae.com.br/sites/PortalSebrae/solucoes_online/software-plano-de-negocio30,2bc0fec6ffae5510VgnVCM1000004c00210aRCRD>. Acesso em: 14 set. 2018.

SERRA, Fernando; TORRES, Maria Candida S.; TORRES, Alexandre Pavan. Administração Estratégica. 4. ed. Florianópolis: Insular, 2009. 224 p.

WILDAUER, E. W. Plano de negócios: elementos constitutivos e processo de elaboração. Curitiba: Ibpex, 2010.

As Referências Bibliográficas devem seguir as normas da ABNT/NBR 6023. 